\title{
O acesso aos Programas de Reabilitação Pulmonar na rede pública de saúde (réplica dos autores)
}

\section{Access to pulmonary rehabilitation programs within the public healthcare service (reply by the authors)}

Em relação à carta ao Editor "O acesso aos Programas de Reabilitação Pulmonar na rede pública de saúde" (referente ao "Guia para prática clínica: Fisioterapia em pacientes com DPOC”, Revista Brasileira de Fisioterapia v. 13, n. 3, p. 183-204, mai/jun 2009), os pontos levantados pelos autores são relevantes, pertinentes ao assunto e merecem especial atenção na realidade brasileira. De fato, existem dificuldades relacionadas ao acesso de pacientes a programas dessa natureza, como as que foram levantadas pelos autores (por exemplo, problemas de transporte e disponibilidade de oxigenioterapia). Existem várias outras ainda. Tais dificuldades fazem parte do dia a dia de pacientes candidatos à reabilitação pulmonar e devem ser consideradas e superadas com o objetivo de garantir o acesso a tal reabilitação, reconhecidamente benéfica. Essa é a nossa realidade brasileira, e temos que melhorá-la da maneira mais consciente possível, o que pode ser feito pelo conhecimento da melhor evidência disponível, mesmo que pareça de difícil aplicação no momento, mas lutando por sua disseminação, defesa e implantação.

De acordo com o abordado pelos autores, concordamos que, apesar de evidências sólidas sobre a boa relação custo-efetividade de PRPs, as características de organização dos serviços de saúde brasileiros, tanto público quanto privado, dificultam a implementação desse tipo de programas de forma ideal. Em outras palavras, isso deixa claro que a luta pela oferta do melhor programa possível de reabilitação não passa apenas por uma batalha científica, mas também por uma batalha política, tanto de conscientização quanto de convencimento.

Indiscutivelmente, a implementação de PRPs de qualidade é um desafio, como bem levantado pelos autores. Cabe a nós, fisioterapeutas, responsáveis pela parte considerada como "pedra principal" do programa (o treinamento físico), aceitar esse desafio. Trabalhando de forma responsável, bem embasada e criteriosa, poderemos sensibilizar não só gestores, mas também os demais profissionais da área da saúde que têm papel no programa de reabilitação a se engajarem nesse processo. Dessa forma, conseguiremos o desenvolvimento dos programas no país, oferecendo serviço de qualidade aos portadores de pneumopatias crônicas, que devem sempre ser o foco principal dos benefícios advindos da implantação de PRPs.

Vanessa Suziane Probst Departamento de Fisioterapia, Universidade Norte do Paraná (UNOPAR), Londrina (PR), Brasil

Fábio Pitta 